\title{
Ground Support Optimisation at Long Shaft
}

\author{
R.J. Butcher, R. Ball, B. Hartmann, J. Currie, G. McLeay Lightning Nickel Pty Ltd, Australia
}

Long Shaft has traditionally been seen as one of the most geotechnically challenging mines in the Kambalda. When mining recommenced in October 2002 the current owners (Lightning Nickel) decided that a different approach was required for the optimisation of the mine's ground support system. This paper describes how Lightning Nickel (LN) has successfully conducted a support optimisation program based on evaluation of the mine's seismic environment, definition of seismic demand on support systems, understanding the geotechnical risk profile of the mine, and the application of the latest research techniques.

\section{INTRODUCTION}

At the present time Long Shaft can be considered as one of the oldest and longest running underground mines in Western Australia. Since mining operations began the extraction of nickel ore from this high grade deposit has been affected by many of the challenges that affect similar deep level mines world wide. In addition the workplace culture had further been influenced by impacts of changes from that of a highly unionised owner operator mining team to a contractual work force. These technical and human impacts were further exacerbated by the need for increased mining efficiencies and reduced costs as workings became deeper. As a result large scale operations were suspended by WMC Resources in 1999. When mining re-commenced in October 2002 the current owners (Lightning Nickel) decided that a different approach was required. This approach is based on the following traditional mining principles:

- Accepting past historical key learning,

- Zero acceptance of unsafe work practices,

- An emphasis on basic mining standards and discipline,

- Tailoring the mine's production to the prevailing geotechnical conditions,

- An owner operator work force,

- A flat management structure,

- An empowered workforce,

- The employment of a highly experienced management team,

- Local community employment,

- Implementation of the latest research,

- Purchase of new trackless equipment to increase efficiencies.

This paper describes how Lightning Nickel (LN) has successfully conducted a support optimisation program as part of the new mining strategy.

\section{MINE OVERVIEW (MODIFIED FROM ANON, 2000)}

The Long Victor Complex (better know as Long Shaft) is located on the eastern flank of the Kambalda Dome. The deposit is a large ribbon like sulphide deposit striking $330^{\circ}$ and dipping at an average of $67^{\circ}$ to the east. The deposit has a strike length of 1,700 metres and a dip length of 600 metres. In general the footwall is comprised of basalt and the hangingwall is comprised of ultramafic. Before operations were suspended by WMC Resources Ltd, $4.5 \mathrm{mt}$ of ore had been mined at an average grade of $3.72 \%$ Nickel to produce $167 \mathrm{Kt}$ of Nickel metal. The Long Victor Complex can be considered as three separate mines, consisting of:

- Long Shaft,

- Victor Decline,

- Victor South Decline.

Long Shaft was first discovered in 1971 with the first ore being produced in October 1979 from the upper levels of the mine, which was serviced by a vertical shaft. The shaft sink commenced in 1975 and was completed in 1978 with the shaft having a final depth of 970 metres below surface.

Long Shaft can be sub-divided into two sections, Long Upper and Long Lower. Mining in the Long Upper levels was by traditional air leg cut and fill and rail haulage methods. Long Lower was commenced using the same mining philosophy as Long Upper but was adapted over time to more mechanised means as technological advances allowed. These methods included jumbo cut and fill and long-hole stoping which were adopted to increase cut and fill stoping rates and extract crown pillars in a safe and efficient manner.

The fill material used in all sections of the Long Shaft mine was de-classified mill tailings. This was provided by the nearby processing plant and supplied via a surface borehole to the underground reticulation system for final placement.

The Victor Decline orebody was commenced in 1989 and access through to Long Lower was gained in 1994. Before this time, the shaft remained the primary means of moving labour, material and rock in and out of the Long Shaft mine.

Long Shaft was placed on care and maintenance in April 1999 with limited stoping being undertaken in 2000. It would appear that the main reasons for the operations being suspended were:

- An aggressive geotechnical environment,

- A resultant high seismic risk,

- Difficulty in co-ordinating mining operations,

- High levels of dilution leading to lower stope grades,

- High mining costs and lower productivity,

- The world nickel price was in a trough cycle.

In October 2001 the mine was sold to LN, a subsidiary of the Independence Group. Initial mining operations focused on the remnant ore blocks at Long Shaft (Figure 1). Development 


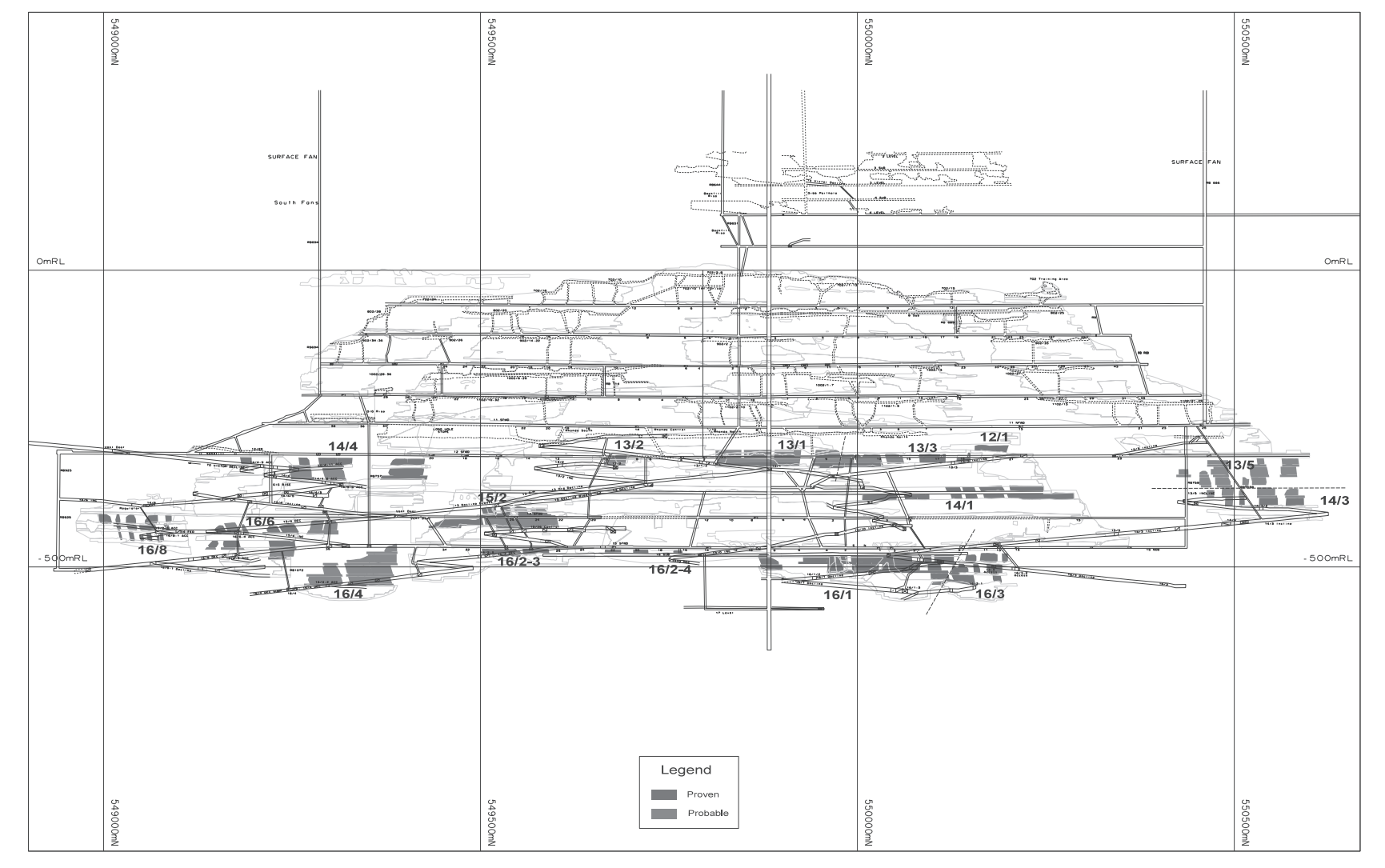

FIG. 1 Long Shaft development showing Long Lower remnant mining blocks

to the new Victor South Mine commenced in 2003, with production planned to begin by the end of 2004. Mining methods have altered slightly since operations began:

- Long Upper air leg cut and fill with pillar retreat re-commenced,

- Long Lower jumbo flat back and up-hole retreat with fill ongoing,

- Victor South room and pillar, jumbo flat back, drift and fill and long-hole stoping with fill.

Mining operations have been undertaken for two years with approximately 264,000 tonnes of ore being mined at an average grade of $3.8 \% \mathrm{Ni}$. It should be noted that the budgeted grade for the 2003/04 financial year was $4.1 \% \mathrm{Ni}$.

\section{GEOTECHNICAL STRATEGY}

Long Shaft gained a reputation throughout the Australian mining industry as a mine that was difficult to operate with an aggressive geotechnical environment. These conditions have resulted from seismic activity associated with highly stressed remnants and porphyry dykes. Major hangingwall failures associated with large stope spans developed in the weak ultramafic hangingwall have also been observed. In 1999 WMC Resources Ltd suspended mining with a view to re-commencing operations using a remnant mining strategy based around long-hole stoping. This planning work was undertaken over a period of two years resulting in the compilation of a Mine Operating Plan, (MOP), (Anon, 2000a).

The MOP identified geotechnical aspects as being critical to successful mining by combining the following factors:

- A general economic sequence of mining,

- Increased levels of support to cater for the deep level geotechnical environment,

- Application of cable bolting in stopes to reduce hangingwall dilution,
- Integration of rib pillars into the mining plan,

- The incorporation of realistic extraction/dilution values into the economic mine plan.

The Long Victor Complex geotechnical environment has been described by Sweby (2002).

When LN recommenced mining operations it was decided to enhance this strategy with the following components:

- Implementation of the geotechnical standards described in the MOP,

- Compilation of a Ground Control Policy for Long Shaft conditions,

- Employment of a Manager with at least 15 years geotechnical experience,

- The determination of production rates compatible with the geotechnical conditions,

- The continuous training of engineers in geotechnical engineering,

- The installation of yielding cable and cone bolts in high risk seismic conditions,

- The training of all mine personnel in geotechnical engineering aspects,

- Ensuring that all support systems were designed to at least Canadian and South African standards,

- Improving and upgrading the mine's seismic system,

- Ongoing seismic risk assessment using the Australian Centre for Geomechanics' MS-RAP program,

- Geotechnical control for high risk areas by the use of A Special Mining Instruction system,

- A policy of ground support using mesh and shotcrete,

- Implementation of the latest research and calibration of numerical models with mining conditions. 
The implementation of this strategy was so successful that it gave rise to the possibility of optimising the mine's ground support systems. This program was undertaken over a period of one year and involved academic research, underground trials and physical tests.

\section{SUPPORT OPTIMISATION PROGRAM}

Since mining operations recommenced at the Long Victor Complex in October 2002 the inherited rock burst resistant support standards have been challenged as being too conservative in terms of the perceived Long Victor Complex seismic environment. The issue of support systems being too conservative generally relates to differing perceptions regarding acceptable operational risk. A further impact highlighting the perception of a conservative support regime is the effect of a single catastrophic event or repeated problems over an extended period of years combined with limited design data. The above has the impact of forcing engineers to design on the "worst case scenario", rather than using a risk-based design approach.

Large magnitude seismic events and continuous problems, as described above, can be associated with:

- Violation of the mining towards the solid rule,

- Incorrect negotiation of geological structures,

- Stope convergence on a central access,

- Out of sequence mining,

- Support systems and mining strategies that are not tailored to the geotechnical environment,

- Arch induced crushing of the caving front,

- Excessive draw rates for caving operations,

- Excessive downward development advance rates for sub level caving operations,

- Non propagation of cave backs,

- The development of excessive block cave undercut spans,

- A combination of the above.

In summary, engineers are forced to use the "worst case" design approach when:

- Strategic geotechnical mine design rules/approaches are not being followed,

- When support systems are not tailored to the geotechnical environment,

- When the geotechnical environment is not under control,

- When there is insufficient data to support the use of a risk based design approach.

Taking note of these issues, the following conditions were adopted for a support optimisation program at the Long Victor Complex:

- Stabilise the geotechnical environment using the strategy as mentioned in section 3,

- Define the historical data base for the design of the current support system,

- Review local experience in similar geotechnical environments,

- Define the mines seismic risk profile and demands for support design,

- Physical testing of the above to confirm support capacities and demands.

Since the first condition had been achieved it was decided that a support system optimisation exercise could be carried out. It should be noted that the mine support systems for high risk ore drives (approximately 40 to $60 \%$ of Long Shaft development) comprised:

- A $75 \mathrm{~mm}$ thick fibrecrete layer,

- Standard pattern of $2.4 \mathrm{~m}$ long split sets and mesh,
- A $1.0 \mathrm{~m} \times 1.5 \mathrm{~m}$ pattern of $2.4 \mathrm{~m}$ long cone bolts,

- A $1.0 \mathrm{~m} \times 1.5 \mathrm{~m}$ pattern of cable bolts for long-hole retreat stopes,

- Support units were spaced approximately $0.45 \mathrm{~m}$ apart in drives.

\subsection{Definition of Historical Data Base for Support Design}

In May 2003 a technical review (Butcher 2003) of the MOP support systems (Anon 2000 b) was carried out. In this regard the review key findings were:

- No support design criterion existed in terms of capacity and demand,

- Numerous support recommendations were made in different documents, thus stacking support systems on previously described recommendations,

- No input values into the standard capacity/demand support equations existed,

- The current seismological regime is less aggressive than experienced during the Long Victor Complex's history,

- The current rock/strain burst rate is $0.3 \%$ of all recorded seismic events,

- The capacity of support systems used in deep level trackless stopes exceeds the Canadian and South African design criteria. In this respect it was estimated that the support systems have factors of safety ranging from 1.7 to 4.5 ,

- The capacity of support systems exceed the maximum practical support limit (MPSL) laid down by the Canadian Rock burst research program (CRRP 1995),

- The energy absorption of the Long system was in the region of $65 \mathrm{~kJ} / \mathrm{m}^{2}$,

- It would appear that long-hole stope support systems were based on a mixture of numerical, experiential and empirical methods. There has never been any attempt made to calibrate the support systems,

- The review showed that the Long stope support systems have factors of safety of 4.5 for the final pillar extraction,

- That the maximum Peak Particle Velocity (PPV) (determined in South Africa (Milev et al., 2000)) for Long design was $3 \mathrm{~m} / \mathrm{s}$. South African conditions were considered to be more aggressive than Long Shaft.

In addition to these aspects a visiting international expert to the mine expressed concern regarding the integration of non-yielding cables into the dynamic support system for the final pillar extraction. Due to these inconsistencies it was therefore decided to fully investigate the historical database for the mine's support system by a program of academic research. An RMIT project (Kinnersly, 2003) was conducted during the latter part of 2003. This project showed:

- Mine support systems were conservatively designed,

- Mine support design information was inconsistent,

- Seismic records indicated that $77 \%$ of events had local magnitudes of less than +0.4 ,

- Calculations indicated that $77 \%$ of events had PPV's of less than or equal to $1.3 \mathrm{~m} / \mathrm{s}$,

- Support systems should have energy absorptions capacities of $22 \mathrm{~kJ} / \mathrm{m}^{2}$ when designing to a magnitude +0.4 (local) seismic event,

- The above determined capacity is approximately $50 \%$ of the support systems designed,

- That ore drives could be supported with split sets, mesh, fibrecrete and cable bolts (no cone bolts) for Long Victor Complex mining conditions. 
It appeared that existing support systems may have been designed to cater for the impacts of magnitude 3.0 seismic events (Local), a peak particle velocity of $5 \mathrm{~m} / \mathrm{s}$ and a dead weight load of 9.7 to 67 tonnes. It further appeared that this design information was based on expert opinion assuming worst case conditions.

It was concluded that potential conditions for support system optimisation existed and the project could be advanced.

\subsection{Local Experience and Yielding Cable Bolt Investigations}

A technical visit was carried out to a nearby mine. This mine was chosen because of a perceived similar seismological history, namely:

- A historical seismic event rate/day ranging from 12 to 200 events. Long Victor Complex's historical rate ranges from 5 to 140 events/day,

- A current seismic event rate/day below 25,

- Similar mean magnitude of events (i.e. ranging from -2 to 1 on the local scale),

- Similar intact rock properties of the ore and country rock,

- Seismic events associated with dykes,

- Similar operational depths and mining methods.

The technical visit showed that long-hole retreat stoping ore drives were only supported with split sets, shotcrete and mesh. These units were installed on similar spacings to that of Long. The major difference was that rock burst resistant support units comprised rings of yielding cable bolts instead of cone bolts. These cable bolts yielded to a maximum of 300 $\mathrm{mm}$. The rock burst resistant support was installed in rings approximately $1.8 \mathrm{~m}$ apart. Recent experience had shown that this support had given adequate excavation protection during a large burst.

An estimate of the support capacity used at the visited mine showed that their system may have support resistances in the region of $200 \mathrm{kN} / \mathrm{m}^{2}$ and energy absorptions of 50 $\mathrm{kJ} / \mathrm{m}^{2}$. Again these values were less than the current Long designs and correspond to the CRRP (1995) guideline. These observations again challenged the need to install support systems whose capacity is greater than that of the guidelines stated by the CRRP. The visit also showed the benefits of using yielding cable bolts at the Long Victor Complex.

It was therefore recommended to conduct a trial to substitute existing separate rings of cone bolts and fully bonded cable bolts with yielding cable bolts in up-hole retreat stopes.

In these situations integrated cone/cable bolt rings were used to achieve support capacities of $50 \mathrm{~kJ} / \mathrm{m}^{2}$ and $293 \mathrm{kN} / \mathrm{m}^{2}$, with these support rings being initially spaced at $1.5 \mathrm{~m}$ intervals. Ore drives were still supported with the standard split sets, mesh and shotcrete.

This support system would have the following advantages:

- The removal of cone bolts from the support pattern ( 4 bolts per $1.5 \mathrm{~m}$ ),

- Greater blast hole ring flexibility as less support units were installed,

- An estimated 3 shifts saved in the stope support cycle,

- A 50\% reduction in cone bolts installed.

The mentioned system was known as the integrated cone/cable bolt ring, and was initially installed in the 14/3-2 stoping block. A full scale mining trial was completed over a period of 7 months for the extraction of this 8,000 tonne block. An additional trial was also undertaken in the 16/6-5 block. This block was chosen due to:
- The high seismic and stress risk associated with the mining of this block,

- The progressive remnant nature of mining,

- That the block would be fully undermined and filled,

- That a mass blast would be undertaken in close proximity to stoping,

- That integrated rings would be exposed to a full range of seismic conditions.

Trials to date have successfully proved that stopping can be conducted with less conservative dynamic support systems and that full implementation of support optimisation findings could be carried out.

\subsection{Mine Seismic Risk Profile and Support Demand}

An international benchmark study was undertaken by the Australian Centre for Geomechanics (ACG 2004). This study benchmarked mines in terms of a Seismic Hazard Scale (SHS) and a Rock Burst Damage Scale. The benchmark outcomes were compared to the mine's seismic hazard. This exercise showed:

- That $40 \%$ of mines studied had a greater seismic hazard than Long Victor,

- That only $20 \%$ of the orebody could be considered as having a high seismic risk,

- $9 \%$ of these high risk stoping areas were being mined at the same time,

- That should a rock burst occur in these high risk areas there was a 0.003 to 0.001 probability that the burst would not be contained by the support system, (or that $99.999 \%$ of bursts would be contained by the mine support systems).

From this exercise it was concluded that the seismic risk profile of Long Shaft was no worse than any other mine in the benchmark study. High risk areas are confined to less than $10 \%$ of the orebody. These conclusions would tend to challenge the original perception that 40 to $60 \%$ of Long Shaft could be classified as high risk (Anon 2000b). The work did show that additional precautions might have to be taken in the high risk areas if support optimisation was to be undertaken.

\subsection{Further Work to Define Support System Demands}

The project work indicated that mine support systems may have been conservatively designed and it was decided to further investigate the PPV values attributed to mine seismic emissions for design purposes. The results of this work are given in Figures 2 and 3. A tunnel fracture zone investigation was also conducted to assess support demands.

The PPV study investigated ground motions from 5,090 seismic events that occurred between 1998 and 2003. From the data above the following was concluded:

- PPV levels of 2 to $5 \mathrm{~m} / \mathrm{s}$ have not been recorded,

- $98 \%$ of daily events have a PPV of less than 1.075 $\mathrm{m} / \mathrm{s}$,

- $92 \%$ have PPV's less than $0.3 \mathrm{~m} / \mathrm{s}$,

- The highest ever event recorded a PPV in the region of $1.8 \mathrm{~m} / \mathrm{s}$ (this magnitude event has a 0.00064 probability of re-occurrence),

- Porphyries and ore drives were seen as the highest risk from bursting,

- $150 \mathrm{~mm}$ to $200 \mathrm{~mm}$ of rock fracture zone could be ejected in porphyries,

- That ore fracture zone thickness of $200 \mathrm{~mm}$ to $500 \mathrm{~mm}$ can be ejected during a seismic event, 


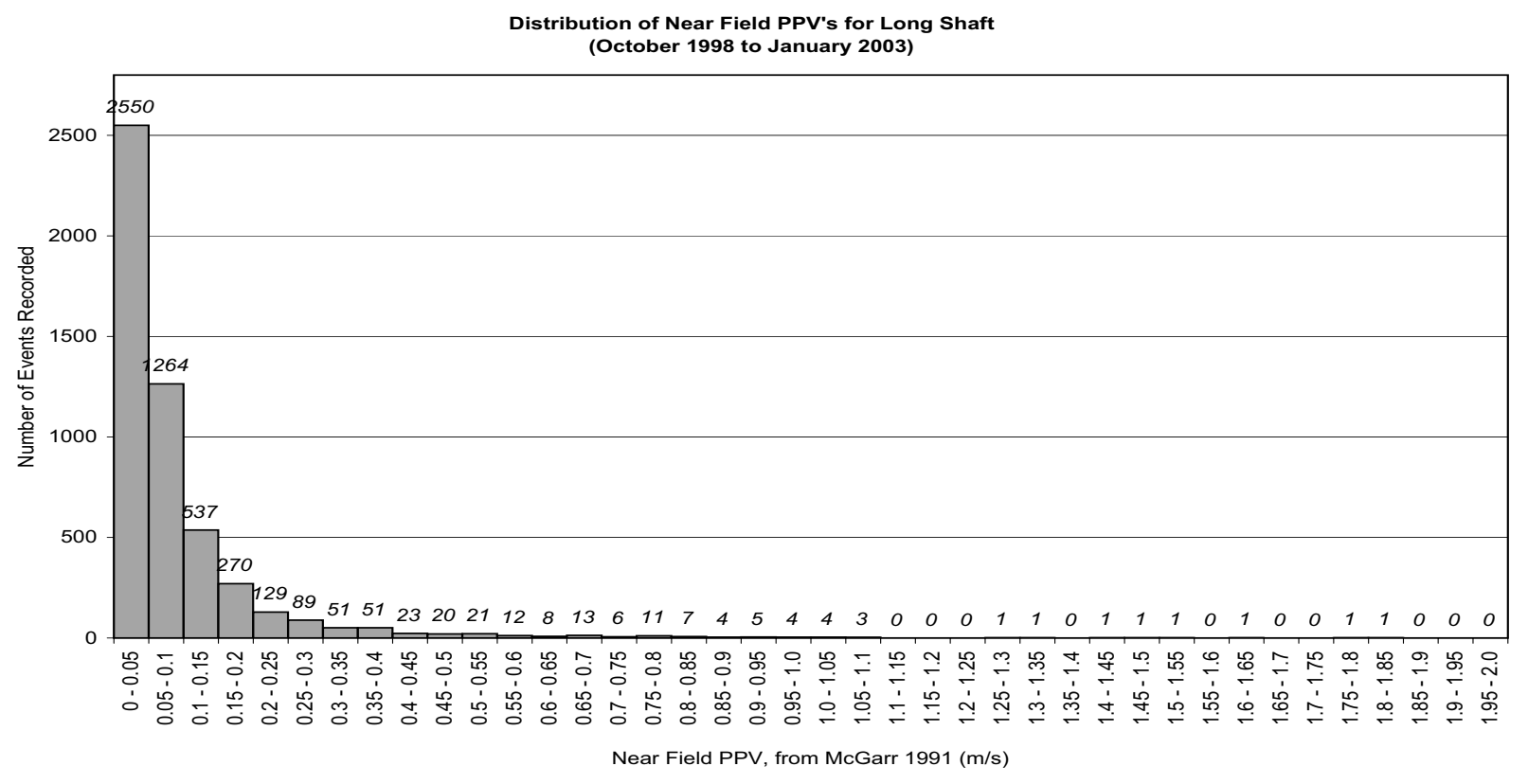

FIG. 2 Long Victor Complex near field PPV's

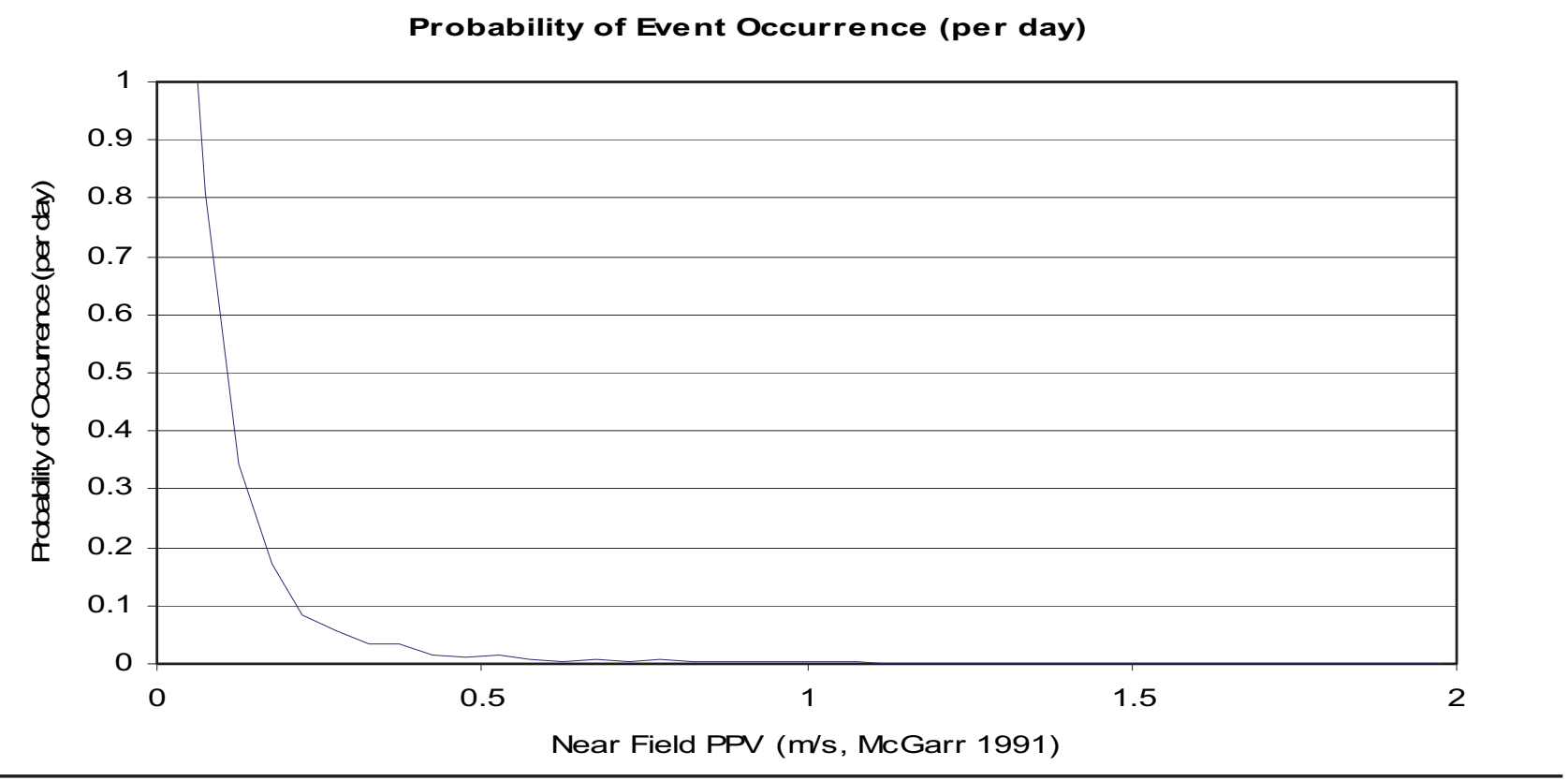

FIG. 3 Daily probability of occurrence

- Therefore the daily energy demands could be less than $5 \mathrm{~kJ} / \mathrm{m}^{2}$ for ore zones and porphyries,

- If the highest single event recorded PPV is used, energy demands $8 \mathrm{~kJ} / \mathrm{m}^{2}$ should be used as the worst case design criterion. These numbers also indicate that bolts, mesh and fibrecrete should be sufficient for general mine use.

The results seriously challenged the original support design in terms of seismic demand. It would appear that the critical issue was related to the shallow depth of the fracture zone surrounding the mine tunnels. Therefore, due to the fact that research had shown a limited zone of damage around tunnels, it was hypothesized that support demands could be substantially reduced. However, in highly fractured conditions, this may mean that ejection velocity should be taken as $2 \times$ PPV to allow for reflected shockwaves, thus resulting in a higher design demand. In this respect, it was decided to maintain the original support systems when mining in closely proximity to the most prominent active geological structures ( 3 areas identified on the mine, $9 \%$ of the mine or the very high risk areas). This was due to the potential for large rockmass wedges and higher PPV's associated in these structures.

The work also showed that two main design main criteria could be determined for the mine. These design criteria are:

- Normal operational support design: PPV of $1 \mathrm{~m} / \mathrm{s}$ and $5 \mathrm{~kJ} / \mathrm{m}^{2}$ energy demand.

- Higher risk support design criteria: PPV $1.8 \mathrm{~m} / \mathrm{s}$ and $8 \mathrm{~kJ} / \mathrm{m}^{2}$ energy demand.

- A maximum fracture zone of $500 \mathrm{~mm}$ was found to be a limiting factor.

However, since these capacities were far less than the original support design criteria, it was decided to approach the consultants that originally designed the Long support systems to request the original design calculations and assumptions. 


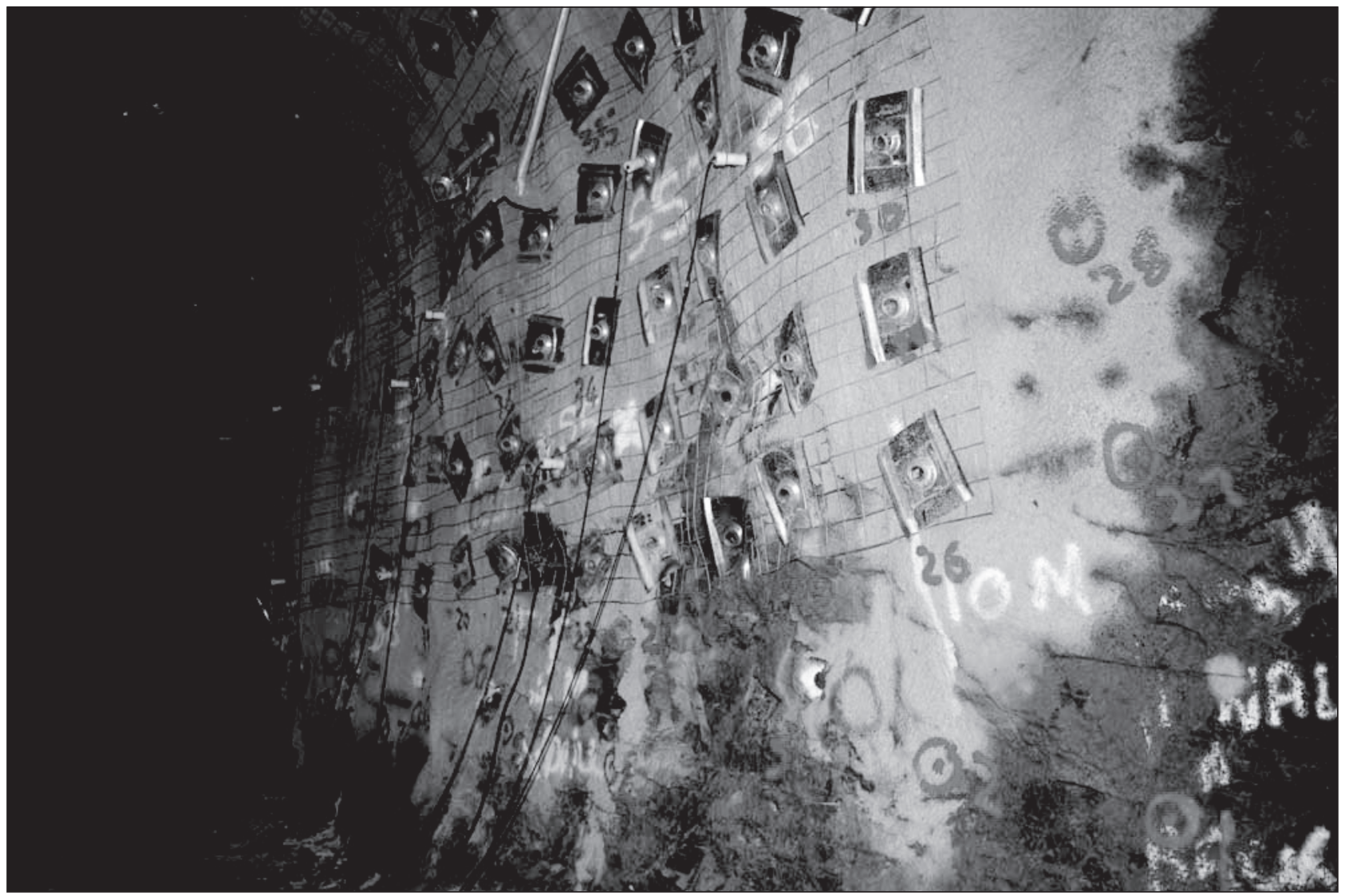

FIG. 4 Trial 1 test site

In this respect a letter was written to the consultants requesting design information, with the following response being received by e-mail:

"The support resistance and energy absorption of the support systems were calculated and found to exceed both the South African and Canadian documented requirements."

Further that:

"Basically the support systems were derived from performance and not designed using calculations."

From the above it can be concluded that the mine systems were experientially derived and that designed support systems exceeded international design standards. In essence they could be considered conservative if the geotechnical conditions are controlled.

Critical issues that required resolution were the impacts of site conditions that could magnify the demand on the support system. This was due to the reflection of the seismic shockwaves. In this respect, experience has shown that ejection velocity can be up to two times the measured PPV, thus resulting in the need for a higher support capacity.

However, the underground observations and previous work did not indicate this was correct. In this respect, a fundamental aim of the optimisation was to confirm if such high ejection velocities were required for design purposes. In order to test this assumption, it was proposed to conduct underground trials.

\subsection{Testing the Demand Assumptions}

The investigative work has showed that mine support systems could be designed for lower seismic demand, thus support optimisation was possible. Experience with

Underground yielding cable bolts trials have shown that support densities could be reduced with no adverse effect in terms of tunnels stability and safety

In order to scientifically test the demand hypothesis given in section 4.4, it was decided to conduct large scale explosive testing of support units underground. A detailed description of these tests is given by Heal et al. (2004). Two deep level porphyry (dominant bursting geotechnical domain) drives were supported and subjected to simulated explosive charge ground motions.

The first trial was conducted in the 13/2 Access (pictured in Figure 4) and the second trial was conducted in the

Rhondo North Access. The aims of the two trials were:

- To determine the impacts of seismic wave attenuation on support system demand.

- To determine the seismic response of tunnels supported with split sets, mesh, cone bolts and fibrecrete (Trial 1),

- To determine if a denser pattern of split sets ( $0.5 \mathrm{~m} \times 0.5 \mathrm{~m}$ pattern) mesh and fibrecrete could be used as a substitute for cone bolting (Trial 1),

- To determine if tunnels supported with bolts, mesh and fibrecrete could withstand ground motions of about $1 \mathrm{~m} / \mathrm{s}$ and energy demands of less than $5 \mathrm{~kJ} / \mathrm{m}^{2}$ (Trial 2),

- To determine if an increased density pattern of split sets, with mesh and fibrecrete is capable of withstanding ground motions of about $1.8 \mathrm{~m} / \mathrm{s}$ and energy demands of $8 \mathrm{~kJ} / \mathrm{m}^{2}$, 
- To indicate what the capacities of the support units are,

- Test the last two systems listed to destruction,

- To try to simulate a $5 \mathrm{~m} / \mathrm{s}$ seismic event.

The results of the underground trials suggested the following:

- The original/current design support systems were conservatively designed,

- The current support systems (bolts, mesh, fibrecrete and cone bolts) are capable of being subjected to ground motions of $2.4 \mathrm{~m} / \mathrm{s}$ and show little to no damage,

- The increased density pattern of split sets, mesh and fibrecrete is capable of being subjected to ground motions of up to $3.6 \mathrm{~m} / \mathrm{s}$ and energy demands of about $10 \mathrm{~kJ} / \mathrm{m}^{2}$,

- Limited magnification of shockwaves with small tunnel fracture zones in terms of ejection velocities,

- Under Long Victor Complex conditions a $0.5 \mathrm{~m} \times 0.5$ $\mathrm{m}$ pattern of split-sets could potentially be substituted for cone bolts,

- The design criteria demands given in section 4.4 would appear realistic for design (i.e. PPV's of 1.0 to $1.8 \mathrm{~m} / \mathrm{s}$ and energy demand levels less than $\left.10 \mathrm{~kJ} / \mathrm{m}^{2}\right)$,

- The support systems consisting of bolts, mesh and fibrecrete are capable of being subjected to ground motions of $1 \mathrm{~m} / \mathrm{s}$ with no evidence of damage,

- The normal and increased density split set patterns are capable of meeting the Long Victor Complex's seismic demands,

- That support optimisation was possible with a full scale mine trial being viable to test the new support design criteria.

\section{CONCLUSIONS}

The support optimisation process at Long Victor showed that the original support systems were conservatively designed for current conditions. The work showed that, to accurately optimise mine support, geotechnical conditions must be under control. The work further showed that support optimisation requires a detailed scientific approach and that this work can not be undertaken with expert opinion only. The work also indicated that support requirements can be reduced if good geotechnical strategies are implemented with shallow tunnel fracture zones. PPV levels of 1.0 to 1.8 $\mathrm{m} / \mathrm{s}$ and energy depands of less than $10 \mathrm{kj} / \mathrm{m}^{2}$ are adequate for design purposes, under such conditions. A further critical issue is the size of the tunnel fracture zone. In this respect, it would appear that there is limited magnification of seismic shockwaves in terms of the ejection velocity with small tunnel fracture zones. It was decided to maintain the original support systems when mining in closely proximity to the most prominent active geological structures (3 areas identified on the mine, $9 \%$ of the mine or the very high risk areas). This was due to the potential large rockmass wedges and high PPV's associated with these areas. The full scale trial has been successfully implemented for a period of 6 months with ground control conditions being maintained. The study work has showed support systems can be reduced in nearly $51 \%$ of the mine.

\section{ACKNOWLEDGMENTS}

The authors would like to thank Lightning Nickel for permission to publish this paper.

\section{REFERENCES}

Anon (2000a) Long Victor Complex Mine Operating Plan, WMC Resources Ltd.

Anon (2000b) Technical Report AMC200046.

ACG (2004) Mining-Induced Seismicity in Underground, Mechanised, Hard Rock Mines: Results of a World Wide Study, Australian Centre for Geomechanics, 2004.

Butcher, R. (2003) Internal Memorandum No RGB392003, dated 31/5/2003.

CRRP (1995) Canadian Rock Burst Research Program 1990-1995, Volumes 1, $2,3$.

Heal, D., Hudyma, M., Potvin, Y., Langille, C., Butcher, R., Ball, R. and Hartmann, B. (2004) Assessing the In situ Performance of Ground Support Systems Subjected to Dynamic Loading, Ground Support in Mining and Underground Construction, (Editors Villaescusa and Potvin). Lisse: Balkema.

Kinnersly, E. (2003) RMIT Design Project 9907673K.

McGarr, A. (1991) Observations Constraining Near-source Ground Motion Estimated from Locally Recorded Seismograms. Journal of Geophysical Research, Vol 96, No. B10, pp. 16495-16508.

Milev, A.M., Spottiswoode, S.M., Noble, B.R., Linzer, L.M., Van Zyl. M. Daehnke, A. and Acheampong, E. (2002) The Meaningful Use of Peak Particle Velocities at Excavation Surfaces for Optimisation of Rock Burst Criteria for Tunnels and Stopes, SIMRAC Project GAP 709, Report No. 2002-305.

Morrison, D., Blake, W. and Hedley, D. (2002) 100 Years of Rockbursting in North American Hard Rock Mines, International Seminar on Deep \& High Stress Mining, Section 2, Australian Centre for Geomechanics Conference, Perth.

Sweby, G. (2002) Kambalda Nickel Operations: Mining in High Stress, Seismically Active Conditions, International Seminar on Deep \& High Stress Mining, paper No 15, Australian Centre for Geomechanics Conference Perth 